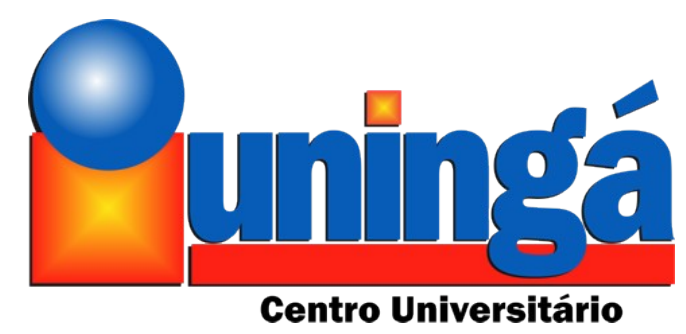

CURSO DE NUTRIÇÃO

Ana Luísa Falcão SANTOS ${ }^{1}$

Maria Cecília MEREGE ${ }^{2}$

\title{
A AGRICULTURA FAMILIAR E A RELAÇÃO COM O PNAE BENEFÍCIOS E DIFICULDADES ENCONTRADAS.
}

${ }^{1}$ Aluna de Graduação em Nutrição do Centro Universitário Ingá

${ }^{2}$ Professora Ms. do Curso de Graduação em Nutrição. 


\section{A AGRICULTURA FAMILIAR E A RELAÇÃO COM O PNAE BENEFÍCIOS E DIFICULDADES ENCONTRADAS.}

Trabalho de Conclusão de Curso apresentado ao Centro Universitário Ingá, como requisito parcial para obtenção do título de Bacharel em Nutrição.

Orientador: Prof. Ms. Maria Cecília Merege

\section{MARINGÁ - PR}




\section{FAMILY AGRICULTURE AND THE RELATIONSHIP WITH PNAE BENEFITS AND DIFFICULTIES FOUND.}

ANA LUÍSA FALCÃO SANTOS. Acadêmico do curso de graduação do curso Nutrição do Centro Universitário Ingá MARIA CECILIA MEREGE. Docente do curso de nutrição do Centro Universitário Ingá

Endereço para correspondência: Rua São João, Número 315, Bairro Zona 7, Maringá, Paraná, Brasil, CEP 87030-200. analuisafs30@gmail.com 


\title{
FAMILY AGRICULTURE AND THE RELATIONSHIP WITH PNAE BENEFITS AND DIFFICULTIES FOUND.
}

\begin{abstract}
RESUMO
Essa pesquisa teve como objetivo investigar as principais dificuldades e benefícios encontrados e enfrentados pela inserção da agricultura familiar no Programa Nacional de Alimentação Escolar (PNAE), voltados á alimentação escolar. A metodologia utilizada a essa pesquisa tratou-se de ensaio crítico realizado com base em revisão da literatura de produções científicas, a fim de obter informações mais detalhadas sobre o PNAE e a Agricultura Familiar. As produções científicas relataram as suas experiências na gestão do Programa Nacional de Alimentação Escolar, apresentando os principais ganhos e dificuldades trazidas com a inserção dos alimentos da agricultura familiar na alimentação escolar. Dentre os ganhos destacam-se o aumento da renda familiar dos agricultores, a qualidade dos alimentos ofertados nas escolas e a melhora da qualidade de vida dos escolares e dos agricultores, nas dificuldades o enfoque ficou para os agricultores, que apresentaram uma dificuldade perante o governo para vender seus produtos, devido as políticas públicas, e também devido ao governo não incluir esses trabalhadores em seus projetos e melhorias que possam acontecer.

Palavras-chave: Agricultura Familiar; PNAE; Alimentação Escolar.
\end{abstract}

\begin{abstract}
This research had as objective to investigate the main difficulties and benefits found and faced by the insertion of the family agriculture in the PNAE, focused on school feeding. The methodology used in this research was a critical test carried out based on a review of the literature on scientific production, in order to obtain more detailed information about PNAE and Family Agriculture. Scientific productions reported their experiences in the management of the National School Feeding Program, presenting the main gains and difficulties brought about by the insertion of food from family farming in school feeding. Among the gains are the increase in the family income of farmers, the quality of food offered in schools and the improvement of the quality of life of schoolchildren and farmers, in the difficulties the focus was on the farmers, who presented a difficulty before the government to sell their products due to public policies, and also because the government does not include such workers in their projects and improvements that may happen.
\end{abstract}

Key words: family farming; pnae; school feeding.

\section{INTRODUÇÃO}

A alimentação é vista como fonte principal da aprendizagem, responsável pelo rendimento e desenvolvimento escolar. A fome tem influência direta sobre o aproveitamento escolar. Resolvida a sensação de fome através de uma alimentação de qualidade, cessam seus efeitos de interferência na disponibilidade neuropsicológica para a aprendizagem (FORMIGA, 2010).

A partir deste conceito surgiu a implementação da alimentação de qualidade nas escolas. A Constituição Federal de 1988 por meio do inciso VII do artigo 208 passou a assegurar o direito à alimentação escolar a todos os alunos do ensino fundamental, cabendo aos entes federados essa promoção. Sendo que com a aprovação da Emenda Constitucional $n^{\circ} 64$ em 2010, a alimentação também passou a ser um direito social, com isso, compreende-se que todas as pessoas têm acesso garantido à alimentação adequada e saudável por meios próprios e sustentáveis (BRASIL, 2012). 
O PNAE é o Programa Nacional de Alimentação Escolar que visa o desenvolvimento, crescimento e aprendizagem dos alunos, sempre em busca do rendimento escolar e da formação de hábitos alimentares saudáveis. O programa foi implantado em 1955 e dentre os objetivos destacam-se; ofertar a alimentação escolar de qualidade e propor ações de educação alimentar e nutricional. São atendidos todos os alunos das redes públicas, entidades filantrópicas e comunitárias, o mesmo conta ainda com o auxílio de outro programa, como o da Agricultura Familiar, no intuito de se desenvolver a prática da ação de propor qualidade alimentar e baixo custo, benefícios para ambos (BRASIL, 2012).

$\mathrm{O}$ agricultor familiar é aquele que desenvolve em suas terras um meio de gerar renda financeira, sendo verificado no Brasil que $84,4 \%$ dos estabelecimentos agropecuários são de agricultores familiares, são cerca de 4,36 milhões de estabelecimentos agropecuários, de acordo com dados do Censo Agropecuário de 2006. A agricultura familiar é responsável pela base econômica de $90 \%$ do municípios brasileiros com até 20 mil habitantes, possuindo assim importância econômica vinculada ao abastecimentos do mercado interno e ao controle de inflação dos alimentos. O principal apoiador da agricultura familiar é o Programa Nacional de Fortalecimento da Agricultura Familiar (Pronaf), que visa promover o desenvolvimento sustentável da agricultura familiar, com ele, os agricultores familiares podem acessar vários meios de renda de acordo como sua necessidade e o seu projeto. Destacam-se projetos destinados para o custeio da safra, atividade agroindustrial, para investimento em máquinas, equipamentos ou infraestrutura, mas para poder ter acesso ao Pronaf a renda bruta anual dos agricultores deve ser de até R $\$ 360.000$ (BRASIL, 2016).

Em busca da melhora do desenvolvimento da educação e da valorização do trabalho dos agricultores, surgiram projetos que visam atingir esses objetivos, e assim a merenda escolar passa a ser vista como instrumento do desenvolvimento local, sem deixar de lado a segurança alimentar, hábitos regionais e respeito a vocação agrícola, compras dentro dos limites geográficos, e utilização dos produtos in natura, dentre estes, a atenção dada a segurança alimentar é de grande importância, devido gerar uma garantia e condições de acesso aos alimentos básicos, seguros e de qualidade, em quantidade suficiente, de modo permanente e sem comprometer o acesso a outras necessidades essenciais, sendo assim para que tudo funcione como esperado, é exigido que exista essa relação entre agricultura, segurança e alimento (TURPIN, 2009).

Esses projetos passam por dificuldades para que sejam concretizados, principalmente o da Agricultura Família, que depende das questões climáticas, além de uma diminuição da população camponesa, reforma agrária, agronegócio, desmatamento e não falta de assistência técnica e extensão rural. A dificuldade se torna ainda maior quando se refere a grandes polos, onde a urbanização é maior e o campo agricultável se limita, assim não atende à demanda de gêneros alimentícios, sendo o principal desafio colocado na implementação da Lei, diga respeito aos municípios de grande população estudantil, uma vez que estes municípios, que geralmente vêm acompanhados de baixa concentração de agricultores familiares nas regiões em que estão localizados possuem sistemas mais complexos de aquisição da alimentação escolar (AZEVEDO, 2014; SANTOS, 2011).

Sendo assim o trabalho em questão teve como objetivo investigar se a implementação da agricultura familiar na alimentação escolar oferece benefícios para quem está aderindo e quais as dificuldades encontradas na aquisição, desde modo, relacionando o PNAE com a Agricultura Familiar.

\section{MATERIAS E MÉTODOS}


Tratou-se de ensaio crítico realizado com base em revisão da literatura de produções científicas indexadas nas bases de dados Scielo, PubMed, Medline e Bireme e em dados oficiais fornecidos pelo Fundo Nacional de Desenvolvimento da Educação/Ministério da Educação/PNAE, referentes às prestações de contas dos órgãos gestores municipais.

Os descritores utilizados enfocaram a agricultura familiar, aquisição de alimentos, seus benefícios para o PNAE e segurança alimentar e nutricional.

O recorte temporal abrangeu o período compreendido entre os anos de 2014 e 2017, sendo que foram excluídos artigos incompletos, indisponíveis, bem como teses, editoriais e dissertações e aqueles que não se adequaram a pesquisa.

\section{RESULTADOS}

Analisando os resultados encontrados nas pesquisas relacionadas entre a relação do PNAE e a agricultura familiar, observou-se os seguintes dados (tabela 01).

\begin{tabular}{|c|c|c|c|c|c|c|c|c|}
\hline Referencia & Ano & Local & Desenho & $\begin{array}{l}\text { Número } \\
\text { de } \\
\text { Sujeitos }\end{array}$ & Fonte & $\begin{array}{l}\text { Característica } \\
\text { da amostra }\end{array}$ & Objetivo & Resultado \\
\hline Azevedo. & 2014 & $\begin{array}{l}\text { Rio } \\
\text { Grande do } \\
\text { Norte }\end{array}$ & $\begin{array}{l}\text { Revisão } \\
\text { bibliográfica }\end{array}$ & $\begin{array}{l}18 \\
\text { artigos }\end{array}$ & $\begin{array}{lr}\text { A relação entre } \\
\text { PNAE e } \\
\text { Agricultura } \\
\text { Familiar: } \\
\text { Virtudes } & \\
\text { problemas } & \text { e } \\
\text { gestão } & \end{array}$ & \begin{tabular}{lr}
\multicolumn{2}{l}{ Nutricionistas e } \\
presidentes do \\
conselho de \\
alimentação \\
escolar
\end{tabular} & $\begin{array}{l}\text { Compreender as } \\
\text { dificuldades da } \\
\text { implementação } \\
\text { dos produtos da } \\
\text { agricultura } \\
\text { familiar. }\end{array}$ & 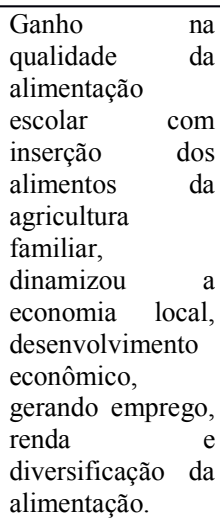 \\
\hline Aroucha. & 2012 & Bahia & $\begin{array}{l}\text { Revisão } \\
\text { bibliográfica }\end{array}$ & $\begin{array}{l}89 \\
\text { artigos }\end{array}$ & $\begin{array}{l}\text { Agricultura } \\
\text { familiar na } \\
\text { alimentação } \\
\text { escolar: Estudo } \\
\text { de oportunidade e } \\
\text { desafios }\end{array}$ & $\begin{array}{lr}\begin{array}{lr}\text { Grupos de } \\
\text { pólos }\end{array} & \text { de } \\
\text { estados } & \\
\text { diferentes, } & 9 \\
\text { pólos } & \\
\text { fornecedores e } & \\
9 \quad \text { pólos } \\
\text { compradores }\end{array}$ & $\begin{array}{lr}\text { Inclusão } & \text { dos } \\
\text { gêneros } & \\
\text { alimentícios } & \text { da } \\
\text { agricultura } & \\
\text { familiar } & \text { na } \\
\text { alimentação } & \\
\text { escolar de várias } \\
\text { naturezas } \\
\text { consolidar } & \text { e } \\
\text { avanços. } & \end{array}$ & $\begin{array}{l}\text { Alimentos sem ou } \\
\text { com pouca } \\
\text { incorporação de } \\
\text { insumos } \\
\text { industriais, menos } \\
\text { uso } \\
\text { mecanização } \\
\text { produz grande } \\
\text { quantidade } \\
\text { alimentos de } \\
\text { forma de } \\
\text { diversificada. }\end{array}$ \\
\hline Turpin. & 2009 & Campinas & $\begin{array}{l}\text { Revisão } \\
\text { bibliográfica }\end{array}$ & $\begin{array}{l}35 \\
\text { artigos }\end{array}$ & $\begin{array}{lr}\text { A alimentação } \\
\text { escolar } & \text { como } \\
\text { fator } & \text { de } \\
\text { desenvolvimento } \\
\text { local por meio do } \\
\text { apoio } & \text { aos } \\
\text { agricultores } & \\
\text { familiares } & \end{array}$ & $\begin{array}{l}\text { Nutricionistas e } \\
\text { diretrizes dos } \\
\text { municípios }\end{array}$ & $\begin{array}{lr}\text { Avaliar } & \\
\text { contribuição } & \text { e } \\
\text { potencialidade do } \\
\text { PNAE e a } \\
\text { importância } \\
\text { econômica } \\
\text { social. }\end{array}$ & $\begin{array}{l}\text { Integração } \\
\text { comunidade e } \\
\text { vários segmentos } \\
\text { governamentais, } \\
\text { fortalecimento da } \\
\text { economia, } \\
\text { diversificação da } \\
\text { produção, redução } \\
\text { do êxodo, } \\
\text { aumento da renda } \\
\text { e da qualidade de } \\
\text { vida. }\end{array}$ \\
\hline $\begin{array}{l}\text { Paulillo, et. } \\
\text { all }\end{array}$ & 2005 & Campinas & $\begin{array}{l}\text { Revisão } \\
\text { bibliográfica }\end{array}$ & $\begin{array}{l}24 \\
\text { artigos }\end{array}$ & $\begin{array}{l}\text { Rede } \\
\text { segurança } \\
\text { alimentar } \\
\text { agricultura } \\
\text { familiar: } \\
\text { merenda escolar } \\
\text { como } \\
\text { instrumento de } \\
\text { desenvolvimento } \\
\text { local }\end{array}$ & $\begin{array}{l}\text { Creches, } \\
\text { escolas } \\
\text { municipais } \\
\text { estaduais }\end{array}$ & $\begin{array}{l}\text { Formação de uma } \\
\text { rede de capital } \\
\text { social em torno de } \\
\text { temática } \\
\text { segurança } \\
\text { alimentar local, } \\
\text { condições } \\
\text { saúde das pessoas } \\
\text { e higiene dos } \\
\text { alimentos dos }\end{array}$ & $\begin{array}{l}\text { Desenvolvimento } \\
\text { de um programa } \\
\text { de segurança } \\
\text { alimentar, } \\
\text { gerando } \\
\text { desenvolvimento } \\
\text { rural } \\
\text { inclusão local, } \\
\text { aumento social, } \\
\text { qualidade }\end{array}$ \\
\hline
\end{tabular}




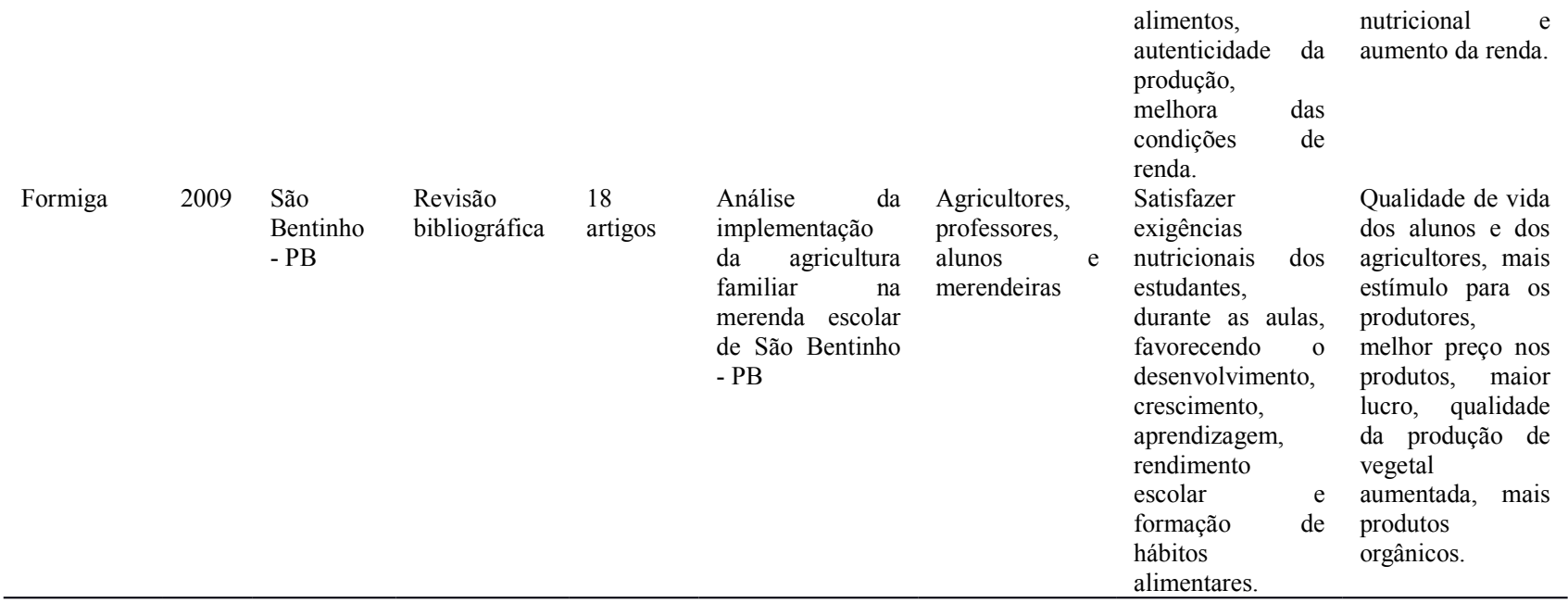

Tabela 01: Características dos estudos sobre a influência do PNAE e a Agricultura Familiar.

\section{DISCUSSÃO}

Dentre os artigos discutidos não encontraram-se muitas diferenças, todos citam os benefícios do PNAE e a Agricultura Familiar, destacam-se os principais como: integração entre comunidades e órgãos governamentais, custo-benefício para os agricultores, melhora na qualidade de vida e nutricional, melhora no preço doa alimentos, qualidade na produção dos alimentos, aumento da renda familiar, inclusão social e desenvolvimento rural local. Os benefícios estão cumprindo com o que o programa emprega, visando a interação entre os dois meios, garantindo uma alimentação saudável e equilibrada, em conjunto com os agricultores que possuem como vantagem o aumento da renda, da produção, e da qualidade de vida, gerando assim um benefício para ambos os lados. (BRASIL, 2012)

De acordo com as pesquisas feitas teve-se noção do ganho na qualidade da alimentação escolar com inserção dos alimentos oriundos da agricultura familiar, sendo assim a inserção desses alimentos enriquece a alimentação, respeita os hábitos alimentares, a cultura e a tradição alimentar da localidade como determina o FNDE (Fundo Nacional de Desenvolvimento da Educação) ao inserir alimentos produzidos por agricultores locais e regionais, afirmando ainda que essa inserção dinamiza a economia local, gerando desenvolvimento econômico, ao gerar emprego e renda. (AZEVEDO, 2014)

Segundo Aroucha (2012), é possível que todas as mudanças propostas pelo programa PNAE sejam cumpridas, mas não em um tempo curto, considerando-se o tempo necessário para a implementação e consolidação de políticas públicas de tamanha amplitude.

Em questão das políticas públicas Paulillo (2005), afirma que um encadeamento agroalimentar não é igual ao outro, que dentro de cada um deles tem uma atuação diferente baseada nas características dadas pela cultura local, ambiente, expectativas econômicas, sendo assim o processo é demorado, pois a operação de políticas públicas para cada caso requer soluções diferenciadas, visto que quando o encadeamento agroindustrial é regional as políticas são mais específicas, pois assim surge uma proximidade maior entre os agricultores facilitando decisões, gerando assim o surgimento de uma nova estrutura, a implementação das políticas contemplam as especificidades da segurança alimentar.

Já Formiga (2010), diz que a partir do seu estudo, que a introdução de gêneros alimentícios proveniente da agricultura familiar na merenda escolar de São Bentinho trouxe melhorias para a qualidade de vida, principalmente dos seus escolares e agricultores familiares rurais, já que os agricultores familiares rurais ficaram mais 
estimulados a produzir alimentos, uma vez que obtiveram a oportunidade de venderem seus produtos a melhores preços, além de melhorarem a qualidade de sua produção vegetal, passando a só cultivar alimentos orgânicos trazendo benefícios para a população e ao meio ambiente. Houve relato de algumas dificuldades encontradas no processo, como a comprovação fiscal, a impossibilidade de vender produtos de origem animal pela ausência do Sistema de Inspeção Municipal em São Bentinho. A economia local foi estimulada durante o ano, os comerciantes relatam terem aumentado seus lucros e percebido um maior poder de compra por parte dos agricultores. Destaca-se o papel do Estado através de ações do Governo por meio do PNAE para redução das desigualdades sociais e superação do problema de acesso ao alimento.

Já Turpin (2009), afirma que um dos pontos principais na avaliação das ações de apoio à agricultura familiar foi a integração entre a comunidade e os vários segmentos governamentais e sociais. Isto não significa que não houve conflitos, ou soluções rápidas para os problemas estruturais, mas sim uma disposição, em que se reconhece a necessidade do cooperativismo para o atendimento às demandas, desenvolvendo a noção de empreendedorismo entre os agricultores familiares.

\section{CONCLUSÃO}

Os achados nesse estudo evidenciaram poucas pesquisas relacionadas a um tema que deveria ser mais explorado visto sua relevância. Com as informações obtidas nessa pesquisa, pode-se compreender os benefícios trazidos com a inserção dos produtos da agricultura familiar na alimentação escolar, assim como as dificuldades encontradas pela gestão dos municípios quanto à inserção desses alimentos,

Ao mesmo tempo é importante salientar sobre a importância do Programa Nacional de Alimentação Escolar - PNAE para a sociedade brasileira no que se refere à promoção da segurança alimentar e nutricional, visto que além de promover o suprimento parcial das necessidades nutricionais dos escolares no período escolar, destaca-se os diversos avanços realizados na estruturação desse programa. Essas reestruturações foram vitais para a construção de um programa tão bem elaborado, e isso, tornou o PNAE um dos mais abrangentes programas sociais do Brasil e do mundo.

Deseja-se que as informações analisadas possam colaborar com a elaboração das políticas públicas tornando mais justas, e de uma possível nova reestruturação que Programa Nacional de Alimentação Escolar uma vez que a agricultura familiar e o PNAE se complementam e assim possa ocorrer melhoras para todos os envolvidos e buscando um governo mais justo, que permita a participação e interação, nas quais, os agricultores possam apresentar as suas especificidades, permitindo que as políticas públicas sejam mais eficientes e contribuindo com a comercialização dos produtos dos pequenos agricultores, gerando renda e desenvolvimento para os municípios brasileiros, além de aumentar a qualidade das alimentações servidas nas escolas.

\section{REFERENCIAS BIBLIOGRAFICAS}

AROUCHA, Edvalda Pereira Torres Lins. AGRICULTURA FAMILIAR NA ALIMENTAÇÃO ESCOLAR: Estudo de oportunidades e de desafios. 2012. 182 f. Dissertação (Mestrado em Ecologia Humana e Gestão Socioambiental) Universidade do Estado da Bahia, Campus VIII, Paulo Afonso/BA. 2012.

AZEVEDO, R. F. O. A RELAÇÃO ENTRE O PNAE E A AGRICULTURA FAMILIAR: Virtudes e problemas de gestão. 41f. Trabalho de Conclusão de Curso, Universidade Federal do Rio Grande do Norte. 2014.

BRASIL. Fundo Nacional de Desenvolvimento da Educação. Aquisição de produtos da agricultura familiar para o programa nacional de alimentação escolar. Brasília: FND: 2012. Disponível em: $\leq$ 
http://www.fnde.gov.br/programas/alimentacao-escolar/agricultura-familiar> . Acesso em: 01 maio 2017.

BRASIL. Fundo Nacional de Desenvolvimento da Educação. Sobre o PNAE. Brasília: FND: 2012. Disponível em: $\quad \leq$ http://www.fnde.gov.br/programas/alimentacao-escolar/alimentacao-escolarapresentacao $>$. Acesso em: 01 maio 2017.

FORMIGA, Walnara Arnaud Moura. Análise da implementação da agricultura familiar na merenda escolar de São Bentinho - PB. UFPB, 2010.

PAULILLO, L. F. et. al. Rede de segurança alimentar e agricultura familiar: a merenda escolar como instrumento de desenvolvimento local. Campinas, 12(1): 26 - 44, 2005.

SANTOS, Luiz Carlos Rebelatto dos. Reflexão sobre o Programa Nacional de Alimentação Escolar PNAE. Brasília: 2011.

TURPIN. M. E. A Alimentação Escolar como Fator de Desenvolvimento Local por meio do Apoio aos Agricultores Familiares. Segurança Alimentar e Nutricional, Campinas, v.16, n.2, p.20-42, 2009. 